\title{
A Simple Approach for Measuring Emission Patterns of Vapor Phase Mercury under Temperature-Controlled Conditions from Soil
}

\author{
Ki-Hyun Kim, ${ }^{1}$ Hye-On Yoon, ${ }^{2}$ Myung-Chae Jung, ${ }^{3}$ Jong-Min Oh, ${ }^{4}$ and Richard J. C. Brown ${ }^{5}$ \\ ${ }^{1}$ Department of Environment and Energy, Sejong University, Seoul 143-747, Republic of Korea \\ ${ }^{2}$ Korea Basic Science Institute, Seoul Center, Anamdong, Seoul 136-713, Republic of Korea \\ ${ }^{3}$ Department of Energy and Mineral Resources Engineering, Sejong University, Seoul 143-747, Republic of Korea \\ ${ }^{4}$ College of Environment and Applied Chemistry, Kyung Hee University, Yongin 449-701, Republic of Korea \\ ${ }^{5}$ Analytical Science Division, National Physical Laboratory, Hampton Road, Teddington TW11 OLW, UK
}

Correspondence should be addressed to Ki-Hyun Kim, khkim@sejong.ac.kr

Received 18 April 2012; Accepted 29 May 2012

Academic Editors: G.-C. Fang, A. S. Hursthouse, and W. Y. Wong

Copyright (C) 2012 Ki-Hyun Kim et al. This is an open access article distributed under the Creative Commons Attribution License, which permits unrestricted use, distribution, and reproduction in any medium, provided the original work is properly cited.

\begin{abstract}
In an effort to study the possible effects of climate change on the behavior of atmospheric mercury ( $\mathrm{Hg}$ ), we built a temperaturecontrolled microchamber system to measure its emission from top soils. To this end, mercury vapour emission rates were investigated in the laboratory using top soil samples collected from an urban area. The emissions of $\mathrm{Hg}$, when measured as a function of soil temperature (from ambient levels up to $70^{\circ} \mathrm{C}$ at increments of $10^{\circ} \mathrm{C}$ ), showed a positive correlation with rising temperature. According to the continuous analyses of the $\mathrm{Hg}$ vapor given off by the identical soil samples, evasion rate diminished noticeably with increasing number of repetitions. The experimental results, if examined in terms of activation energy (Ea), showed highly contrasting patterns between the single and repetitive runs. Although the results of the former exhibited Ea values smaller than the vaporization energy of $\mathrm{Hg}$ (i.e., $<14 \mathrm{Kcal} \mathrm{mol}^{-1}$ ), those of the latter increased systematically with increasing number of repetitions. As such, it is proposed that changes in the magnitude of Ea values can be used as a highly sensitive criterion to discriminate the important role of vaporization from other diverse (biotic/abiotic) processes occurring in the soil layer.
\end{abstract}

\section{Introduction}

As one of the most toxic and bioconcentrated trace metals in the aquatic and terrestrial food chain, the environmental behavior and the associated atmospheric and terrestrial cycle of mercury $(\mathrm{Hg}$ ) have become a growing theme in many fields of geosciences, in particular in atmospheric sciences [1]. Focused research efforts have yielded fruitful outcomes in estimating global and/or regional scale $\mathrm{Hg}$ budgets and in explaining the behavior of $\mathrm{Hg}$ in various media [25]. Despite the progresses achieved over recent years, it is still difficult to provide a concrete assessment of the relationships between the scale of natural and anthropogenic source processes. Confusion surrounding this issue is as a result of man-made sources showing significant variation, brought about by rapid changes in $\mathrm{Hg}$ control and abatement strategies. Moreover, it is also recognized that the relative sizes of the different natural (in particular terrestrial) sources are not yet firmly established. This is clearly important in order to account for their relative contributions to the global Hg budget [6].

The soil-to-air exchange of $\mathrm{Hg}$ is characterized by a reproducible diurnal trend correlated with changes in solar radiation, while also being affected by many other environmental variables (e.g., soil temperature, wind speed, vertical mixing, latent energy, precipitation, vegetation surface, etc.) [7-9]. All the processes leading to active transfer of $\mathrm{Hg}$ across an air-surface boundary may occur many times within the geochemical cycle via (re-) emission and (re-) deposition, and so forth. This becomes particularly important if the natural budgets of $\mathrm{Hg}$ are compared across its natural reservoirs; $\mathrm{Hg}$ in soil $\left(1.2 \times 10^{6} \mathrm{Mg}\right)$ is estimated to exceed substantially its sum in the ocean $\left(3.6 \times 10^{5} \mathrm{Mg}\right)$ and atmosphere $\left(6 \times 10^{3} \mathrm{Mg}\right)[10]$. As such, it is reasonable to 


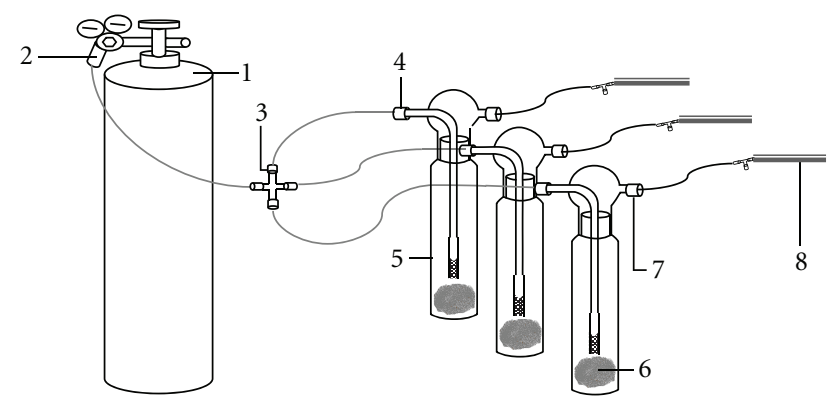

FIGURE 1: Illustration of the sampling apparatus for sediment flux analysis using an impinger vessel as a microflux chamber (1) ultrapure air tank; (2) ultrapure air flow regulator; (3) flow control/regulator towards the 3 impingers; (4) impinger inlet; (5) impinger bottle (6) sediment sample (50 g); (7) impinger outlet; and (8) adsorption tubes.

infer that the role of $\mathrm{Hg}$ in soil will become even more prominent with the progress of climate change.

Although the emission of $\mathrm{Hg}$ from soil is dependent on many variables [11], we examined the fundamental properties of $\mathrm{Hg}$ exchange from soil in response to temperature rise in order to demonstrate the performance of our novel apparatus. Whilst this effect is well known (being examined previously (e.g., [12]), we have now designed a new and simple apparatus to examine the phenomenon on some different aspects. To analyze the interaction between $\mathrm{Hg}$ behavior and changing soil temperature, a novel impinger system modified for flux measurements (e.g., a microchamber system) was used to quantify its exchange rates, using soil samples collected in an urban area. The results of this analysis will be useful to assess the basic aspects of $\mathrm{Hg}$ exchange under the temperature-regulated conditions and may help predict the increased burden of $\mathrm{Hg}$ in the atmosphere as a result of average increases in ambient temperatures.

\section{Materials and Methods}

2.1. Sample Collection and Analysis. In order to obtain the $\mathrm{Hg}$ emission data from soil systems in relation to rising soil temperature, a simple experimental system was devised to allow the simultaneous collection of $\mathrm{Hg}$ samples from three impingers (as microchambers) in combination with a temperature controlling water bath (Figure 1). In order to improve the detection limits for the $\mathrm{Hg}$ released from soil samples, the total volume of air passing through the impinger was maintained at $120 \mathrm{~L}$ ( $4 \mathrm{hrs}$ of sampling at a flow rate of $\left.0.5 \mathrm{~L} \mathrm{~min}^{-1}\right)$. In light of the volume of the impinger used in this research $(0.5 \mathrm{~L})$, one would expect a chamber turnover time of the order of one to two minutes with the flow being expected to be laminar through the impinger. Whilst chamber turnover will have an influence on $\mathrm{Hg}$ flux, we do not consider this parameter further in this study. It is because this turnover rate is fairly high and, in any case, this is a comparative laboratory study.

As sampling duration is relatively long for each run (e.g., $4 \mathrm{hrs}$ duration for the acquisition of a single datapoint at a given temperature), all of our analysis collected data
TABLE 1: Basic soil parameters and Hg content measured from 3 soil samples investigated in this study.

\begin{tabular}{lcccc}
\hline Parameter unit & $\mathrm{pH}$ & $\begin{array}{c}\mathrm{LOI}^{\mathrm{a}} \\
(\%)\end{array}$ & $\begin{array}{c}\mathrm{CEC}^{\mathrm{b}} \\
\mu \mathrm{eqg}{ }^{-1}\end{array}$ & $\begin{array}{c}\mathrm{Hg} \\
\mathrm{Mg} \mathrm{kg}^{-1}\end{array}$ \\
\hline S-1 & 7.01 & 6.03 & 142.9 & 3.309 \\
S-2 & 6.34 & 4.36 & 42.6 & 2.942 \\
S-3 & 6.47 & 5.68 & 79.3 & 2.787 \\
\hline
\end{tabular}

${ }^{a}$ LOI: loss on ignition measured after 6 hrs at $450^{\circ} \mathrm{C}$.

${ }^{\mathrm{b}} \mathrm{CEC}$ : cation exchange capacity.

from 3 samples at a time. For simple comparison, a total of 3 different soil samples were taken from 3 different spots (several meters apart from each other) in the front yard of Young Sil Building, Sejong University, Republic of Korea during January 2010. All of these soil samples represent the upper (top) soil layers (e.g., O, A, and B horizons; 0-30 cm). Care was taken to minimize the intermixing of soil materials using a hand spade. The basic soil properties determined for these 3 soil samples are given in Table 1 along with the concentrations of $\mathrm{Hg}$ within the soil. The results indicate that the $\mathrm{Hg}$ contents of the three soil samples are similar and all in the range 2.8 to $3.3 \mathrm{mg} \mathrm{kg}^{-1}$, rather elevated compared to background soil $\mathrm{Hg}$ concentrations $\left(<0.2 \mathrm{mg} \mathrm{kg}^{-1}\right)$.

As shown in Figure 1, the system is built to simultaneously undertake flux measurements in each of the 3 impingers, under the same temperature conditions. Our triplicate sampling system was hence used to simultaneously measure the $\mathrm{Hg}$ emission rates for three different soil sample masses: 0 (blank), 50, and $100 \mathrm{~g}$. This chamber system thus provided blank levels for the correction of analytical values derived at two soil quantities (50 and $100 \mathrm{~g}$ ) as required. To initiate each experiment, the inlet and outlet of each impinger are connected to the purging system (cylinder filled with ultrapure air) and the sample collection system ( $\mathrm{Au}$ amalgam tube), respectively (Figure 1). The ultrapure air from the cylinder is then released and brought into each of the 3 impingers at a fixed flow rate of $500 \mathrm{~mL} \mathrm{~min}^{-1}$ for 4 hours, to make a total sample volume of $120 \mathrm{~L}$ at each temperature.

The exchange rates of $\mathrm{Hg}$ for a given soil sample were quantified continuously by raising the soil temperature from room temperature up to $70^{\circ} \mathrm{C}$ in $10^{\circ} \mathrm{C}$ intervals. The flux data taken from the blank samples averaged $0.11 \pm 0.08 \mathrm{ng} \mathrm{m}^{-3}$ $(n=27)$ which corresponds to 2 or $0.7 \%$ of $\mathrm{Hg}$ levels determined from 50 and $100 \mathrm{~g}$ soils, respectively. These blank values for each experiment were used for the adjustment of the $\mathrm{Hg}$ values measured for soil samples with 50 and $100 \mathrm{~g}$. As the temperature for each experiment was held constant for $4 \mathrm{hrs}$, it typically took 3 to 4 days to acquire the data over a full temperature range for a given soil sample. Once a new set of experiments started, impingers containing soil samples were left in the laboratory with their open ends sealed by Mylar film. All the samples were kept at room temperature under the standard fluorescent lamp in the laboratory throughout the study period. A fluorescent tube is known to be a more diffuse and physically larger light source than an incandescent lamp. All experiments 
were hence conducted without the complete removal of light intensity. Although light has been identified to be one of the most sensitive variables controlling $\mathrm{Hg}$ emission behavior, this study was mainly intended to measure the effect of soil temperature change on its emission rate without the control of light conditions-which were constant throughout.

The analysis of the $\mathrm{Hg}$ collected in the adsorption tubes was performed using thermal desorption $\left(350^{\circ} \mathrm{C}\right)$ and detection at a wavelength of $253.7 \mathrm{~nm}$ with a nondispersive double beam and flameless atomic absorption mercury analyzer (WA-4, Nippon Instrument Co., Japan). The specification and results of analytical performance for the comparable instrumental setup can be found in our previous studies, described elsewhere [13-15]. The method detection limit (DL) of the system was slightly variable from day-to-day but did not exceed $10 \mathrm{pg}$ of $\mathrm{Hg}$ mass; this DL is moderately higher than those reported by the similar instrumental systems in our previous study (e.g., [13]) —but much lower than any of the concentration expected in this study. DL values were obtained as 3.14 times the standard deviation values of 7 repeat runs at intensities just distinguishable from system blanks.

2.2. Derivation of $\mathrm{Hg}$ Flux. The emission rate of $\mathrm{Hg}$ was quantified by inputting the measured $\mathrm{Hg}$ concentration determined from each experiment into the following formula:

$$
F=C\left(L+\frac{Q}{A}\right)
$$

where $F=\mathrm{Hg}$ flux in dimensions of mass per area per time (ng $\mathrm{m}^{-2} \mathrm{~min}^{-1}$ ); $\mathrm{C}=\mathrm{Hg}$ concentration exiting the chamber $\left(\mathrm{ng} \mathrm{m}^{-3}\right) ; Q=$ flow rate passing through the chamber $\left(\mathrm{m}^{3} \mathrm{~min}^{-1}\right)$; and $A=$ inner surface area of the chamber $\left(\mathrm{m}^{2}\right)$.

By assuming that the loss term is almost negligible (because we assume-and have evidence- that the chamber walls have been fully conditioned with $\mathrm{Hg}$ during setup and validation such that there is no longer any net transfer of $\mathrm{Hg}$ from gaseous to adsorbed phases), the flux values of $\mathrm{Hg}$ can be approximated by multiplying $\mathrm{Hg}$ concentration exiting the chamber by the ratio $Q / A$, that is, $F=Q C / A$.

\section{Results and Discussion}

3.1. The Pattern of the Hg Emission Data in Relation to Soil Quantity Criterion. In the initial stage of our experiments, in order to evaluate the emission of vapor phase $\mathrm{Hg}$ from different soil samples, we measured $\mathrm{Hg}$ fluxes from 3 independent soil samples labeled as S1, S2, and S3. In the second stage of our experiment, the soil emission rate for one of those three soil samples (S3) was measured consecutively three times. Each of these experimental runs covered the full temperature range (from room temperature to $70^{\circ} \mathrm{C}$ in 10 degree steps) and was compared to examine the trend over repetitive runs. Although temperature was a key variable in our investigations, we also briefly examined the effect of sample quantity on observed emission rates. As a result of this objective, our experiments were conducted using
2 different soil quantities: 50 and $100 \mathrm{~g}$. To resolve any differences in the emissions from these two soil weights, these results were treated independently and are summarized in Tables 2 and 3, respectively. For completeness, the $\mathrm{Hg}$ concentrations used for the derivation of the flux values are also presented.

The volume of the impinger chamber system used in this study is not large enough to contain more than $100 \mathrm{~g}$ of soils. As such, the data presented in this preliminary study is not able to examine the effect of soil sample quantities other than at those two values (50 and $100 \mathrm{~g}$ )-especially weights in excess of $100 \mathrm{~g}$. Nonetheless, comparison of these data indicates that the emissions of $\mathrm{Hg}$ from soil under these experimental conditions may be affected greatly by the weight of soil placed in the impinger. Most importantly, it is apparent that the experimental data obtained using the $100 \mathrm{~g}$ soil samples tend to exhibit fairly systematic trends of increasing emissions as temperature increased (Figure 2) similarly to the original observations of this type [12]. This is however not the case for the $50 \mathrm{~g}$ samples, which did not show any $\mathrm{Hg}$ emissions up to $50^{\circ} \mathrm{C}$ in the initial experiments. In addition, $\mathrm{Hg}$ flux data from the different $50 \mathrm{~g}$ samples showed highly contrasting patterns; although the maximum emission value of the S1 sample was seen at $50^{\circ} \mathrm{C}$, those of $\mathrm{S} 3$ occurred at the lowest temperature of $25^{\circ} \mathrm{C}$. Moreover, in our repeated analysis of $50 \mathrm{~g}$ samples, only small quantities of $\mathrm{Hg}$ were emitted consistently after $60^{\circ} \mathrm{C}$. As such, the results derived using $50 \mathrm{~g}$ soil samples suggest that the emission of $\mathrm{Hg}$ from this quantity of soil is less likely to exhibit and maintain a systematic trend. As seen in Table 2, the results from all three $50 \mathrm{~g}$ samples confirm irregular patterns of $\mathrm{Hg}$ emission with increasing temperature. The effect observed with sample mass may be a function of the exposed surface area (which is constant for each mass-and constrained by the cross-sectional area of the impinger) to volume (which changes for each mass) ratio exhibited by each sample, although this hypothesis needs further testing.

3.2. Effect of Soil Temperature Rise on $\mathrm{Hg}$ Emission. As plotted in Figure 2(a), the trend of increasing $\mathrm{Hg}$ emission with increases in soil temperature from $100 \mathrm{~g}$ soil samples is distinctive and systematic. The results presented in Table 3 indicate that $\mathrm{Hg}$ emissions gradually increased with increasing temperature without any noticeable exceptions. As the $\mathrm{Hg}$ emission trends from the $50 \mathrm{~g}$ soil samples were rather complicated to interpret, we focused mainly on the emission data from the $100 \mathrm{~g}$ soil samples to evaluate the relationship between temperature and $\mathrm{Hg}$ emissions. The results of the initial runs from the 3 soil samples (S1, S2, and S3) indicated consistently that the $\mathrm{Hg}$ emission rates increased almost exponentially with temperature, peaking in the range of 50 to $70^{\circ} \mathrm{C}$. However, the magnitude of the emissions from the 3 samples differs moderately, for example, the maximum emission value of $126 \mathrm{ng} \mathrm{m}^{-2} \mathrm{~h}^{-1}$ for S2 in contrast to the maximum for the other two samples of near to $600 \mathrm{ng} \mathrm{m}^{-2} \mathrm{~h}^{-1}$ (Figure 2(a)). In addition, the results of 3 continuous runs of the S3 sample (S3-1, S3-2, and S3-3) indicate that the $\mathrm{Hg}$ can be released continuously by forced extraction (e.g., via repetitive heating). However, it 
TABLE 2: Summary of experiments using three soil samples with a total weight of $50 \mathrm{~g}^{\mathrm{a}}$.

(a) Hg concentration exiting the chamber $\left(\mathrm{ng} \mathrm{m}^{-3}\right)$

\begin{tabular}{|c|c|c|c|c|c|}
\hline Temp & $C(\mathrm{~S} 1)^{\mathrm{b}}$ & $C(\mathrm{~S} 2)$ & $C(\mathrm{~S} 3-1)$ & $C(\mathrm{~S} 3-2)$ & $C(\mathrm{~S} 3-3)$ \\
\hline 25 & 7.065 & 3.046 & 6.568 & NM & NM \\
\hline 30 & 10.412 & 2.607 & 4.206 & $\mathrm{DL}$ & $\mathrm{DL}$ \\
\hline 40 & 21.194 & 6.159 & 3.941 & DL & DL \\
\hline 50 & 32.524 & 4.160 & 1.822 & DL & DL \\
\hline 60 & 13.024 & 6.565 & 1.386 & 0.064 & 1.025 \\
\hline 70 & NM & 4.217 & 0.883 & 0.372 & 3.745 \\
\hline
\end{tabular}

(b) Hg emission flux $\left(\mathrm{ng} \mathrm{m}^{-2} \mathrm{~h}^{-1}\right)$

\begin{tabular}{lcccc}
\hline Temp & $F(\mathrm{~S} 1)$ & $F(\mathrm{~S} 2)$ & $F(\mathrm{~S} 3-1)$ & $F(\mathrm{~S} 3-2)$ \\
\hline 25 & 70.2 & 30.3 & 65.3 & \\
30 & 103.5 & 25.9 & 41.8 & \\
40 & 210.6 & 61.2 & 39.2 & \\
50 & 323.2 & 41.3 & 18.1 & 0.6 \\
60 & 129.4 & 65.2 & 13.8 & 3.7 \\
70 & & 41.9 & 8.8 & 3.2 \\
\hline
\end{tabular}

(c) Relationship between $1 / T$ versus $\ln$ (emission flux)

\begin{tabular}{lcccc}
\hline $1 / T($ abs $)$ & $\ln (F(\mathrm{~S} 1))$ & $\ln (F(\mathrm{~S} 2))$ & $\ln (F(\mathrm{~S} 3-1))$ & $\ln (F(\mathrm{~S} 3-2))$ \\
\hline 0.0034 & 4.2514 & 3.4100 & 4.1785 & \\
0.0033 & 4.6392 & 3.2546 & 3.7329 & \\
0.0032 & 5.3500 & 4.1142 & 3.6677 & \\
0.0031 & 5.7782 & 3.7219 & 2.8961 & -0.4466 \\
0.0030 & 4.8630 & 4.1780 & 2.6226 & 1.3071 \\
0.0029 & & 3.7354 & 2.1721 & 2.3207 \\
\hline
\end{tabular}

${ }^{\mathrm{a}}$ Three soil samples are named as S1, S2, and S3, and the number of repetition is given after the hyphen.

b Initiation dates for each experiment: S1 (22 December 2009), S2 (30 December 2009), S3-1 (26 January 2010), S3-2 (2 February 2010), and S3-3 (11 February 2010).

was very clear that the magnitude of $\mathrm{Hg}$ emission diminished systematically with increasing numbers of repeated heating cycles (Figure $2(\mathrm{~b})$ ). If the emission values at $70^{\circ} \mathrm{C}$ are compared, the values measured were 357 (first heating cycle), 116 (second heating cycle), and $67 \mathrm{ng} \mathrm{m}^{-2} \mathrm{~h}^{-1}$ (third heating cycle). Nonetheless, the results from these repeated runs suggest that soil may act as a significant source of $\mathrm{Hg}$ to the atmosphere particularly as a result of changes in the surrounding climate.

In recent years, the important role of terrestrial source processes in $\mathrm{Hg}$ geochemistry has been highlighted because of its close linkage with the global warming trend. Because of its unique vaporization properties, the cycling of $\mathrm{Hg}$ is expected to share some common features with that observed for greenhouse gas pollutants [16]. The increasing evasion of $\mathrm{Hg}$ with rising temperature has in fact been demonstrated from both water and soil layers [17]. Indeed Figure 3 shows data from the UK Heavy Metals Monitoring Network Air Quality Network station at Runcorn [18], where historical industrial processes have led to contamination of the soil by mercury [19]. In such case, it can be clearly seen that the mercury vapor levels measured in air correlate well $\left(R^{2}=0.8\right)$ with the average temperature at the monitoring sites (offset by one month to allow for the lag in the ground warming and cooling). That the correlation is worse when the temperature is not offset by one month $\left(R^{2}=0.5\right)$ is a good indication that temperature is a major factor in causing more mercury evasion from soil and therefore increasing the measured total gaseous mercury (TGM) concentration in surrounding air, and not simply other factors such as light and ozone concentration which would have a more temporally direct effect.

To learn more about the factors regulating $\mathrm{Hg}$ emissions from soil, we examined our experimental results in relation to activation energy $\left(E_{a}\right)$. As documented by many previous studies, mercury fluxes over soils (and to a lesser extent ambient concentrations) generally exhibit a strong exponential relationship with changing soil temperature $[12,20,21]$. This temperature dependence of $\mathrm{Hg}$ emissions has often been accounted for by an interactive relationship between the physicochemical properties of elemental mercury (high vapor pressure and low water solubility) and biotic/abiotic processes occurring in the soil layer. As the mechanism of $\mathrm{Hg}$ emission from soil is particularly sensitive to temperature rises, its potential can be expressed in terms of activation energy $\left(E_{a}\right)$ with the aid of the Arrhenius equation $[6,22] . E_{a}$ values have thus often been derived to estimate the partitioning of $\mathrm{Hg}$ evasion from soil between (a) physical vaporization 
TABLE 3: Summary of experiments using three soil samples with a total weight of $100 \mathrm{~g}^{\mathrm{a}}$.

(a) $\mathrm{Hg}$ concentration exiting the chamber $\left(\mathrm{ng} \mathrm{m}^{-3}\right)$

\begin{tabular}{|c|c|c|c|c|c|}
\hline Temp & $C(\mathrm{~S} 1)^{\mathrm{b}}$ & $C(\mathrm{~S} 2)$ & $C(\mathrm{~S} 3-1)$ & $C(\mathrm{~S} 3-2)$ & $C(\mathrm{~S} 3-3)$ \\
\hline 25 & 17.101 & 3.684 & 7.502 & NM & $\mathrm{NM}$ \\
\hline 30 & 14.702 & 3.116 & 4.782 & 0.089 & 0.016 \\
\hline 40 & 48.746 & 7.647 & 9.515 & 0.328 & 0.131 \\
\hline 50 & 60.455 & 12.350 & 34.146 & 1.316 & 0.699 \\
\hline 60 & 38.728 & 10.452 & 56.805 & 4.208 & 2.559 \\
\hline 70 & NM & 12.696 & 35.930 & 11.619 & 6.715 \\
\hline
\end{tabular}

(b) Hg emission flux $\left(\mathrm{ng} \mathrm{m}^{-2} \mathrm{~h}^{-1}\right)$

\begin{tabular}{|c|c|c|c|c|c|}
\hline Temp & $F(\mathrm{~S} 1)$ & $F(\mathrm{~S} 2)$ & $F(\mathrm{~S} 3-1)$ & $F(\mathrm{~S} 3-2)$ & $F(\mathrm{~S} 3-3)$ \\
\hline 25 & 169.9 & 36.6 & 74.5 & NM & NM \\
\hline 30 & 146.1 & 31.0 & 47.5 & 0.9 & 0.2 \\
\hline 40 & 484.4 & 76.0 & 94.6 & 3.3 & 1.3 \\
\hline 50 & 600.7 & 122.7 & 339.3 & 13.1 & 6.9 \\
\hline 60 & 384.8 & 103.9 & 564.5 & 41.8 & 25.4 \\
\hline 70 & & 126.2 & 357.0 & 115.5 & 66.7 \\
\hline
\end{tabular}

(c) Relationship between $1 / T$ versus $\ln$ (emission flux)

\begin{tabular}{lccccc}
\hline $1 / T(\mathrm{abs})$ & $\ln (F(\mathrm{~S} 1))$ & $\ln (F(\mathrm{~S} 2))$ & $\ln (F(\mathrm{~S} 3-1))$ & $\ln (F(\mathrm{~S} 3-2))$ & \\
\hline 0.0034 & 5.1354 & 3.6003 & 4.3114 & -0.1230 & -1.8362 \\
0.0033 & 4.9842 & 3.4329 & 3.8612 & 1.1805 & 0.2617 \\
0.0032 & 6.1829 & 4.3306 & 4.5492 & 2.5705 & 3.9384 \\
0.0031 & 6.3981 & 4.8099 & 5.8269 & 3.7333 & 3.2360 \\
0.0030 & 5.9528 & 4.6431 & 6.3359 & 4.7488 & 4.2005 \\
0.0029 & & 4.8376 & 5.8778 & \\
\hline
\end{tabular}

${ }^{\mathrm{a}}$ Three soil samples are named S1, S2, and S3, and the number of repetition is given after the hyphen.

bInitiation dates for each experiment: S1 (22 December 2009), S2 (30 December 2009), S3-1 (26 January 2010), S3-2 (2 February 2010), and S3-3 (11 February 2010).

(due to its volatility) and (b) other soil processes with more biological/chemical nature (e.g., photochemical reduction (abiotic) or biological mediation (biotic)).

Previous estimates of activation energy showed that the values measured from various environmental surfaces can fall in a relatively wide range: $17.3 \pm 7.7$ in background forest [23], 20.53 over pasture fields [17], $25.8 \pm 2.6$ in contaminated soils [6], $28.0 \pm 5.7$ in mercuriferous volcanic soils [24], and $29.6 \pm 1.0 \mathrm{Kcal} \mathrm{mol}^{-1}$ in lake surfaces in Sweden [22]. If this type of approach is extended to encompass a variety of environmental substances (e.g., lake sand, coated glass, and organic material) and between light and dark conditions, a broad range of $E_{a}$ values are found from 5.2 to $152 \mathrm{Kcal} \mathrm{mol}^{-1}$ [20]. However, in light of the fact that the enthalpy of $\mathrm{Hg}^{\mathrm{o}}$ vaporization is $\sim 14 \mathrm{Kcal} \mathrm{mol}^{-1}$, the major driving force of $\mathrm{Hg}$ emission in each case may be estimated with respect to this reference $E_{a}$ value. As such, our experimental $E_{a}$ results were derived based on two-types of approaches (either the initial runs of each of 3 samples or repeated runs from a single soil sample (S3)), they can also be evaluated against such criterion.

Fitting the data obtained to the Arrhenius equation, the $E_{a}$ values for the single run (S1, S2, and S3) samples were computed as $6.74,6.49$, and $10.5 \mathrm{Kcal} \mathrm{mol}^{-1}$ (Figure 4).
These data are far lower than the enthalpy of vaporization for $\mathrm{Hg}$ and of those determined in previous studies. However, the results from the repeated runs exhibit a contrasting trend; their $E_{a}$ values increase systematically with the number of repetitions such that the values obtained were 10.5 (S3repeat 1), 25.4 (S3-repeat 2), and $31.2 \mathrm{Kcal} \mathrm{mol}^{-1}$ (S3repeat 3). It is thus suggested that the emissions of $\mathrm{Hg}$ from single (or first) runs can be dominated directly by vaporization, whereas emissions observed from continuous runs are to be driven directly by the control of abiotic parameters. Once the majority of $\mathrm{Hg}$ emission is accounted for by vaporization, the effect of other processes becomes more prominent in regulating subsequent emissions.

As the results of our study show, emissions of $\mathrm{Hg}$ from continuous runs require an extra source of energy other than vaporization. Gustin et al. [20] explained the lightinduced photochemical reduction of reactive divalent $\mathrm{Hg}$ to elemental $\mathrm{Hg}$ as the important sources of soil-derived $\mathrm{Hg}$. These authors observed that the magnitude of lightenhanced emissions for natural substrates were 1.5 to 116 times larger than that under the dark conditions. In addition, based on the findings of the relative enhancement of $E_{a}$ during daytime, they postulated that the release of $\mathrm{Hg}$ from such substrates may increase due to phytoreduction 


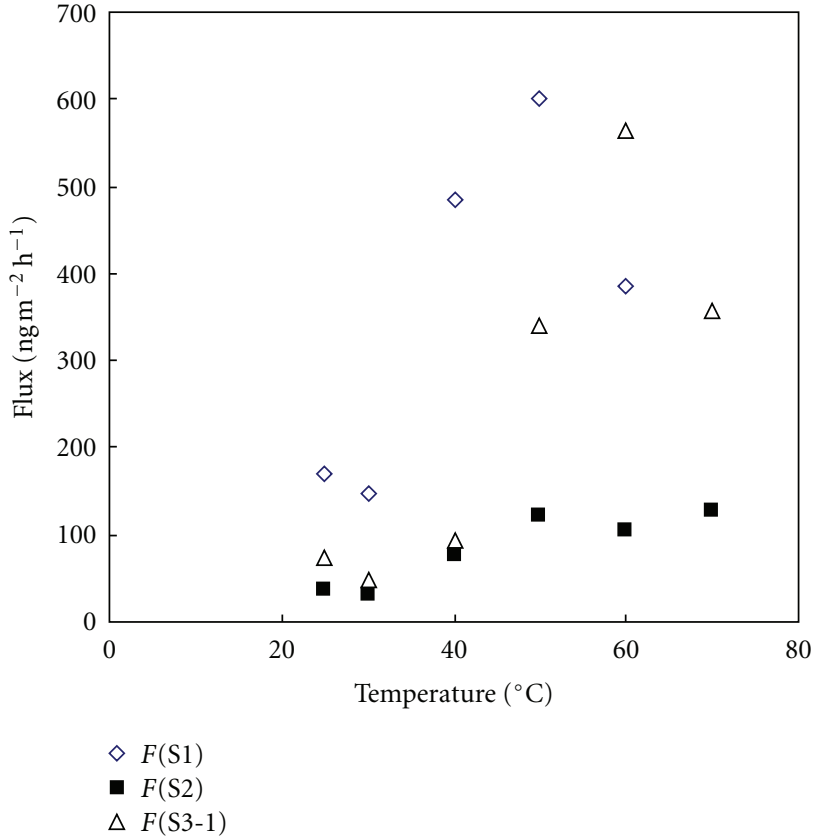

(a)

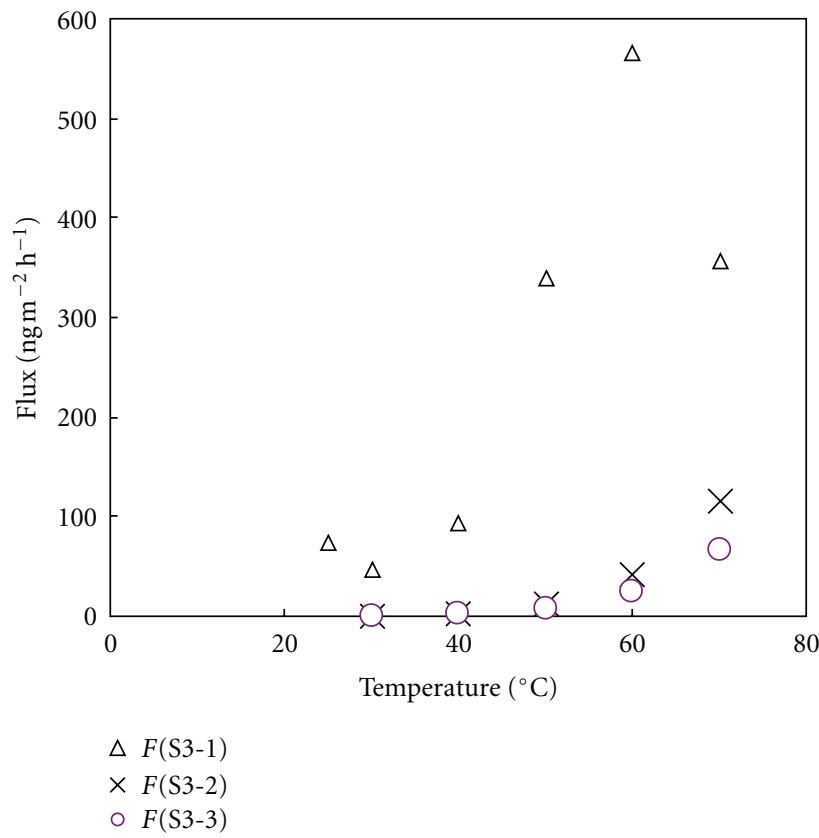

(b)

Figure 2: Relationship between temperature and $\mathrm{Hg}$ flux $\left(\mathrm{ng} \mathrm{m}^{-2} \mathrm{~h}^{-1}\right)$ from $100 \mathrm{~g}$ soil samples: (a) $\mathrm{Hg}$ flux values derived from the initial run of three samples (upper) and (b) Hg flux values derived from the repetitive runs of S3 sample.

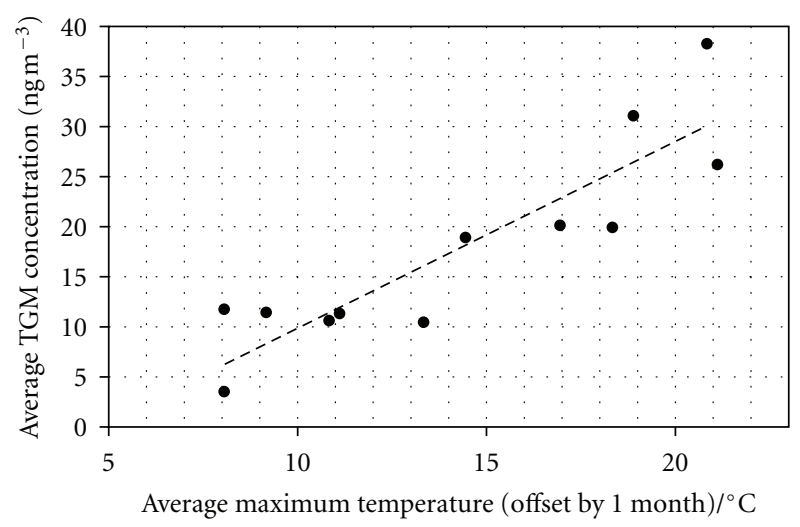

FIGURE 3: The average maximum monthly temperature (offset by one month to allow for the lag in the ground warming and cooling) against the average monthly total gaseous mercury concentration recorded at the UK Heavy Metals Monitoring Air Quality Network station at Runcorn during 2010. The best linear fit to the data is shown $\left(R^{2}=0.8\right)$ as the dotted line.

when exposure to sunlight. Likewise, Choi and Holsen [25] observed that the $\mathrm{Hg}$ emissions were very sensitive to UV-B exposure $(302 \mathrm{~nm})$, while there were no such effects with UVA $(365 \mathrm{~nm})$. Based on this finding, they suggested that the role of abiotic parameters is more prominent in controlling $\mathrm{Hg}$ emissions than biotic ones.

\section{Conclusions}

The present study was undertaken to investigate the factors involved in the emissions of $\mathrm{Hg}$ from soil to atmosphere and

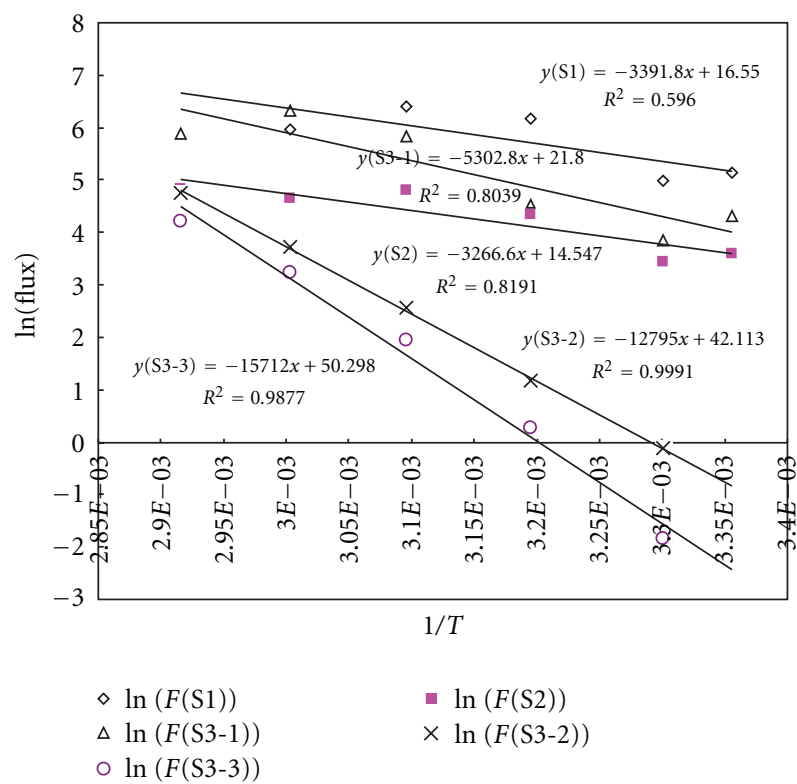

FIgure 4: Relationship between $1 / T$ (abs) and $\ln (\mathrm{Hg}$ flux) to derive activation energy $\left(E_{a}\right)$.

demonstrate the use of a novel apparatus to measure this. In an effort to elucidate the fundamental features of this process, we measured $\mathrm{Hg}$ emission fluxes from soil samples using a novel microchamber system across varying soil temperatures from room temperature up to $70^{\circ} \mathrm{C}$. The emission rates of $\mathrm{Hg}$ were initially measured once from each of the three soil samples, and then one of these samples was selected and measured repeatedly (i.e., up to 3 consecutive runs) to 
determine the forced emission patterns with increased soil temperature.

The results of our laboratory study consistently indicate that there is an exponential increase in $\mathrm{Hg}$ emissions with rising temperature. In addition, the emission rates of $\mathrm{Hg}$, measured repetitively using the same soil samples, were subject to a stepwise reduction with each subsequent heating cycle. The temperature dependence of $\mathrm{Hg}$ emissions, if evaluated in terms of activation energy $\left(E_{a}\right)$, complies well with general expectations. The computed $E_{a}$ values indicate that the emission of $\mathrm{Hg}$ from soil is initially controlled by vaporization, while the subsequent reemission is driven by the biotic/abiotic processes occurring in the soil layer. It is thus reasonable to infer that the mercury liberated during the second and third repeats could be from continued vaporization of $\mathrm{Hg}$ more deeply absorbed within the soil structure as opposed to from biotic activity. As such, changes induced by soil temperature rises can be as important as that of light exposure to the mechanism of $\mathrm{Hg}$ emissions from soil. This further suggests that $\mathrm{Hg}$ emissions flux from soils induced solely by either one of the two variables (temperature and light) may differ to a certain degree. This notwithstanding, both of these two abiotic variables are likely to interact effectively in the conversion of an increased percentage of oxidized $\mathrm{Hg}$ species into an elemental form resulting in subsequent emissions of the $\mathrm{Hg}$ from soil. Moreover, the results presented also make clear that temperature increases caused by climate changes will act to shift the equilibrium between mercury in air and mercury in soil towards higher concentrations in air. For real soils in higher latitudes, the expected range of average temperature might be in the range -10 to $30^{\circ} \mathrm{C}$, whereas in more equatorial regions temperature might be expected to be in the range 15 to $55^{\circ} \mathrm{C}$. Therefore, the results from this study apply to many of the surface temperatures found around the globe. However, we would expect that the results presented could be extrapolated to cover more extreme temperatures, as required.

\section{Acknowledgments}

This work was supported by the National Research Foundation of Korea (NRF) Grant funded by the Ministry of Education, Science and Technology (MEST) (no. 20100007876). The second author acknowledges the support made by a grant from the Korea Basic Science Institute (Project no. T32603). Laboratory analysis of Hg data by Dr. $\mathrm{H}$. Nguyen is greatly appreciated.

\section{References}

[1] L.-Q. Xu, X.-D. Liu, L.-G. Sun et al., "A 700-year record of mercury in avian eggshells of Guangjin Island, South China Sea," Environmental Pollution, vol. 159, no. 4, pp. 889-896, 2011.

[2] L. Liu, Y.-W. Lam, and W.-Y. Wong, "Complexation of 4,4'di(tert-butyl)-5-ethynyl-2,2' -bithiazole with mercury(II) ion: synthesis, structures and analytical applications," Journal of Organometallic Chemistry, vol. 691, no. 6, pp. 1092-1100, 2006.
[3] J.-S. Lee, M. S. Han, and C. A. Mirkin, "Colorimetric detection of mercuric ion $\left(\mathrm{Hg}^{+}\right)$in aqueous media using DNAfunctionalized gold nanoparticles," Angewandte Chemie, vol. 46, no. 22, pp. 4093-4096, 2007.

[4] L. Liu, W.-Y. Wong, Y.-W. Lam, and W.-Y. Tam, "Exploring a series of monoethynylfluorenes as alkynylating reagents for mercuric ion: synthesis, spectroscopy, photophysics and potential use in mercury speciation," Inorganica Chimica Acta, vol. 360, no. 1, pp. 109-121, 2007.

[5] W.-Y. Wong, "Mercury alkynyls as versatile templates for new organometallic materials and polymers," Coordination Chemistry Reviews, vol. 251, no. 17-20, pp. 2400-2427, 2007.

[6] S. E. Lindberg, P. J. Hanson, T. P. Meyers, and K.-H. Kim, "Air/surface exchange of mercury vapor over forests-the need for a reassessment of continental biogenic emissions," Atmospheric Environment, vol. 32, no. 5, pp. 895-908, 1998.

[7] X. Song and B. Van Heyst, "Volatilization of mercury from soils in response to simulated precipitation," Atmospheric Environment, vol. 39, no. 39, pp. 7494-7505, 2005.

[8] L. Zhang, L. P. Wright, and P. Blanchard, "A review of current knowledge concerning dry deposition of atmospheric mercury," Atmospheric Environment, vol. 43, no. 37, pp. 58535864, 2009.

[9] J. Rinklebe, A. During, M. Overesch et al., "Dynamics of mercury fluxes and their controlling factors in large $\mathrm{Hg}$ polluted floodplain areas," Environmental Pollution, vol. 158, no. 1, pp. 308-318, 2010.

[10] N. E. Selin, D. J. Jacob, R. M. Yantosca, S. Strode, L. Jaeglé, and E. M. Sunderland, "Global 3-D land-ocean-atmosphere model for mercury: present-day versus preindustrial cycles and anthropogenic enrichment factors for deposition," Global Biogeochemical Cycles, vol. 22, no. 2, Article ID GB2011, 2008.

[11] M. S. Gustin, M. Engle, J. Ericksen, S. Lyman, J. Stamenkovic, and M. Xin, "Mercury exchange between the atmosphere and low mercury containing substrates," Applied Geochemistry, vol. 21, no. 11, pp. 1913-1923, 2006.

[12] M. S. Gustin, G. E. Taylor Jr., and R. A. Maxey, "Effect of temperature and air movement on the flux of elemental mercury from substrate to the atmosphere," Journal of Geophysical Research D, vol. 102, no. 3, pp. 3891-3898, 1997.

[13] K.-H. Kim and M.-Y. Kim, "The exchange of gaseous mercury across soil-air interface in a residential area of Seoul, Korea," Atmospheric Environment, vol. 33, no. 19, pp. 3153-3165, 1999.

[14] K.-H. Kim, M.-Y. Kim, and G. Lee, "The soil-air exchange characteristics of total gaseous mercury from a large-scale municipal landfill area," Atmospheric Environment, vol. 35, no. 20, pp. 3475-3493, 2001.

[15] K.-H. Kim, R. Ebinghaus, W. H. Schroeder et al., "Atmospheric mercury concentrations from several observatory sites in the Northern Hemisphere," Journal of Atmospheric Chemistry, vol. 50, no. 1, pp. 1-24, 2005.

[16] D. J. Jacob and D. A. Winner, "Effect of climate change on air quality," Atmospheric Environment, vol. 43, no. 1, pp. 51-63, 2009.

[17] L. Poissant and A. Casimir, "Water-air and soil-air exchange rate of total gaseous mercury measured at background sites," Atmospheric Environment, vol. 32, no. 5, pp. 883-893, 1998.

[18] R. J. C. Brown, R. E. Yardley, D. Muhunthan et al., "Twentyfive years of nationwide ambient metals measurement in the United Kingdom: concentration levels and trends," Environmental Monitoring and Assessment, vol. 142, no. 1-3, pp. 127-140, 2008. 
[19] J. C. Dearden, "Personal communication with R. J. C. Brown," 2011.

[20] M. S. Gustin, H. Biester, and C. S. Kim, "Investigation of the light-enhanced emission of mercury from naturally enriched substrates," Atmospheric Environment, vol. 36, no. 20, pp. 3241-3254, 2002.

[21] S. E. Lindberg, H. Zhang, A. F. Vette, M. S. Gustin, M. O. Barnett, and T. Kuiken, "Dynamic flux chamber measurement of gaseous mercury emission fluxes over soils: part 2-effect of flushing flow rate and verification of a two-resistance exchange interface simulation model," Atmospheric Environment, vol. 36, no. 5, pp. 847-859, 2002.

[22] Z. F. Xiao, J. Munthe, W. H. Schroeder, and O. Lindqvist, "Vertical fluxes of volatile mercury over forest soil and lake surfaces in Sweden," Tellus B, vol. 43, no. 3, pp. 267-279, 1991.

[23] K.-H. Kim, S. E. Lindberg, and T. P. Meyers, "Micrometeorological measurements of mercury vapor fluxes over background forest soils in Eastern Tennessee," Atmospheric Environment, vol. 29, no. 2, pp. 267-282, 1995.

[24] S. M. Siegel and B. Z. Siegel, "Temperature determinants of plant-soil-air mercury relationships," Water, Air, and Soil Pollution, vol. 40, no. 3-4, pp. 443-448, 1988.

[25] H.-D. Choi and T. M. Holsen, "Gaseous mercury emissions from unsterilized and sterilized soils: the effect of temperature and UV radiation," Environmental Pollution, vol. 157, no. 5, pp. 1673-1678, 2009. 


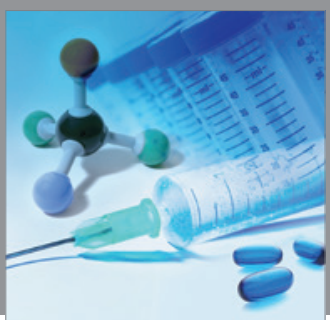

International Journal of

Medicinal Chemistry

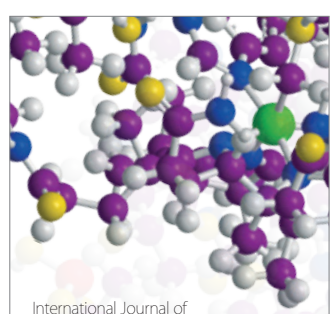

Carbohydrate Chemistry

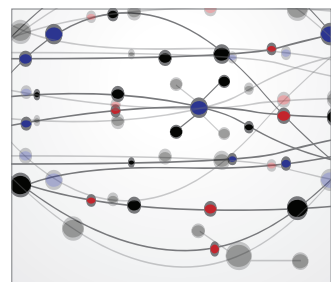

The Scientific World Journal
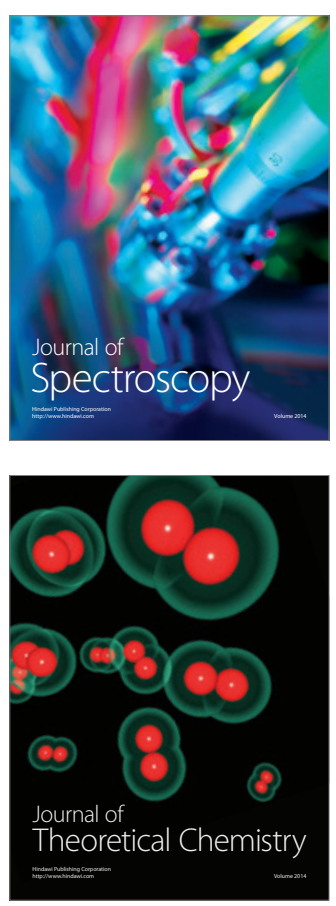
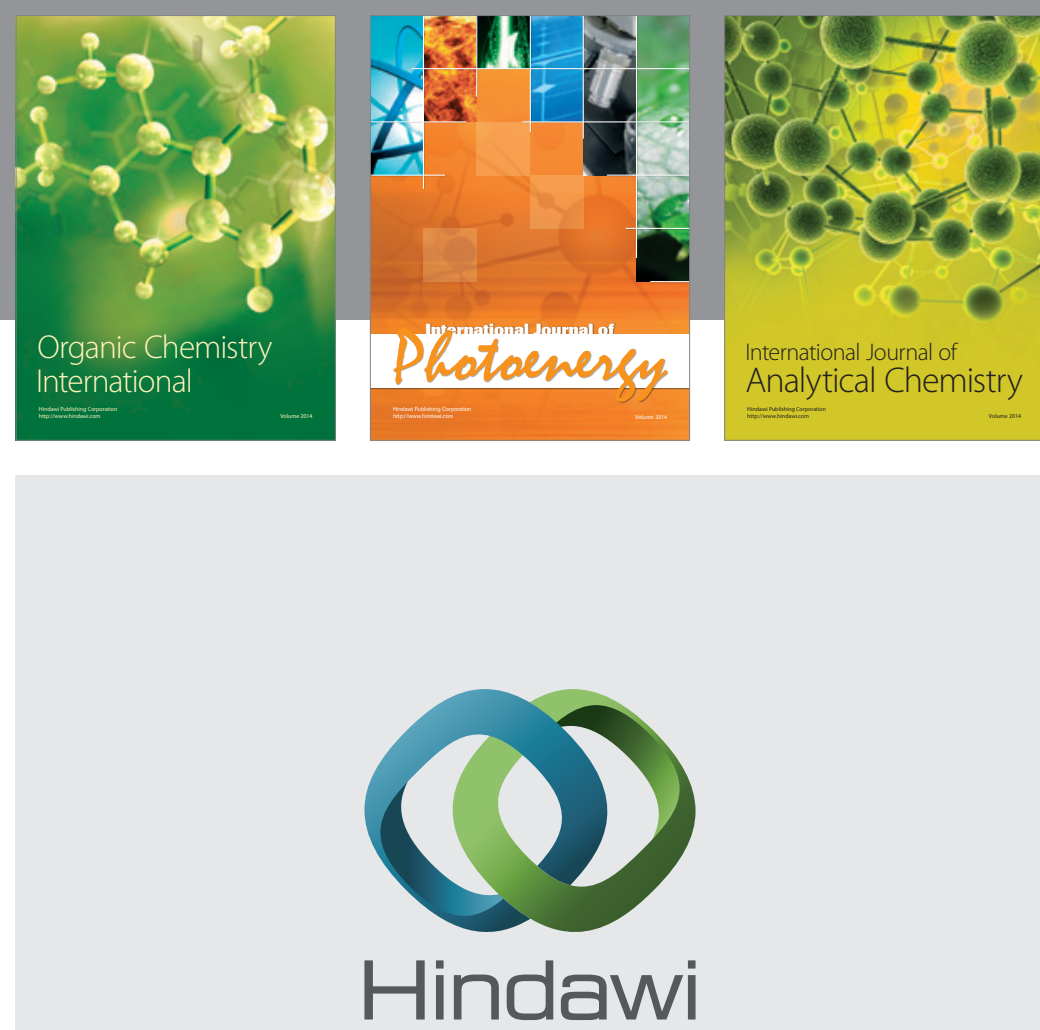

Submit your manuscripts at

http://www.hindawi.com
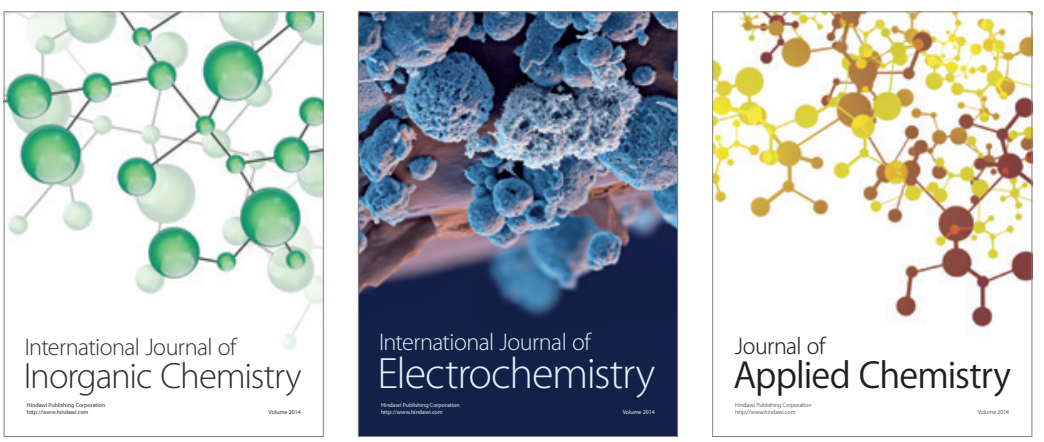

Journal of

Applied Chemistry
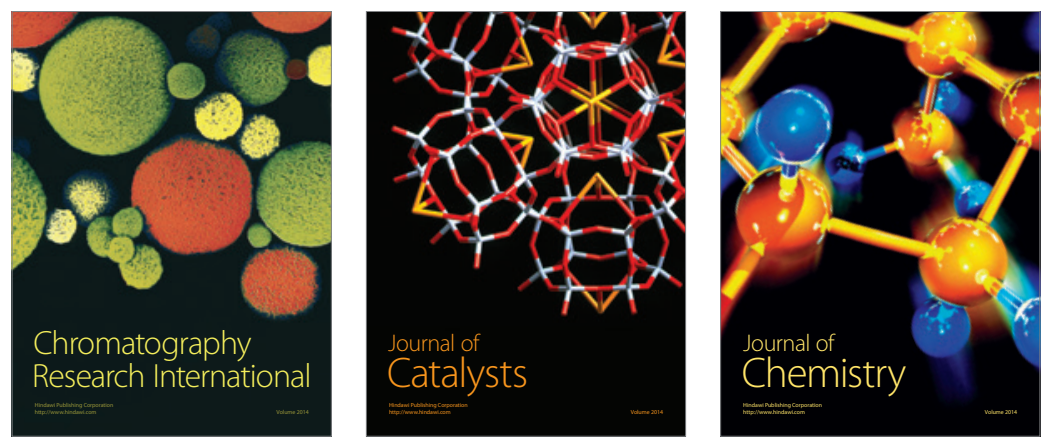
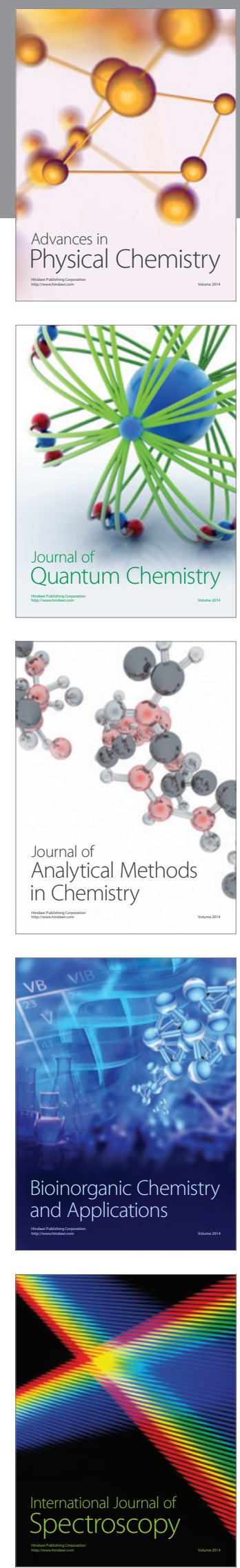